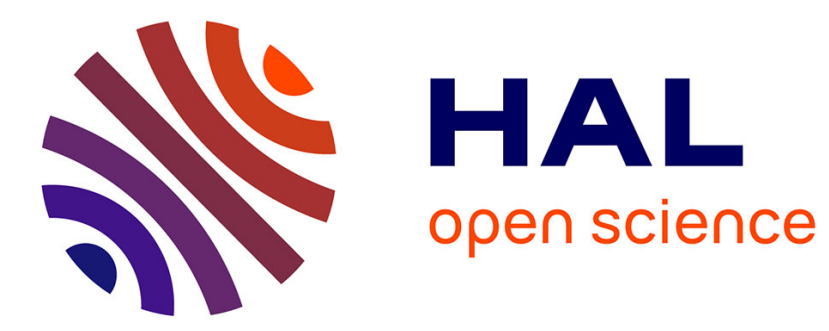

\title{
Cutter-workpiece engagement calculation in 3-axis ball end milling considering cutter runout
}

Lotfi Sai, Rami Belguith, Maher Baili, Gilles Dessein, Wassila Bouzid

\section{To cite this version:}

Lotfi Sai, Rami Belguith, Maher Baili, Gilles Dessein, Wassila Bouzid. Cutter-workpiece engagement calculation in 3-axis ball end milling considering cutter runout. Journal of Manufacturing Processes, 2019, 41, pp.74-82. 10.1016/j.jmapro.2019.03.025 . hal-02134719

\section{HAL Id: hal-02134719 \\ https://hal.science/hal-02134719}

Submitted on 20 May 2019

HAL is a multi-disciplinary open access archive for the deposit and dissemination of scientific research documents, whether they are published or not. The documents may come from teaching and research institutions in France or abroad, or from public or private research centers.
L'archive ouverte pluridisciplinaire HAL, est destinée au dépôt et à la diffusion de documents scientifiques de niveau recherche, publiés ou non, émanant des établissements d'enseignement et de recherche français ou étrangers, des laboratoires publics ou privés. 


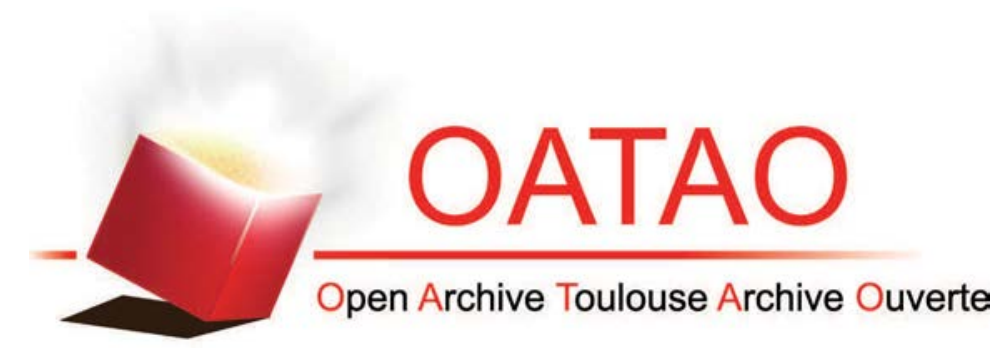

\section{Open Archive Toulouse Archive Ouverte (OATAO)}

OATAO is an open access repository that collects the work of some Toulouse researchers and makes it freely available over the web where possible.

This is an author's version published in: https://oatao.univ-toulouse.fr/23731

Official URL : https://doi.org/10.1016/j.jmapro.2019.03.025

\section{To cite this version :}

Sai, Lotfi and Belguith, Rami and Baili, Maher $\leftrightarrows$ and Dessein, Gilles $\leftrightarrows$ and Bouzid, Wassila Cutter-workpiece engagement calculation in 3-axis ball end milling considering cutter runout. (2019) Journal of Manufacturing Processes, 41. 74-82. ISSN 1526-6125

Any correspondence concerning this service should be sent to the repository administrator: tech-oatao@listes-diff.inp-toulouse.fr 


\title{
Cutter-workpiece engagement calculation in 3-axis ball end milling considering cutter runout
}

\author{
Sai Lotfi ${ }^{\mathrm{a}, *}$, Belguith Rami ${ }^{\mathrm{a}, \mathrm{b}}$, Baili Maher ${ }^{\mathrm{b}}$, Dessein Gilles ${ }^{\mathrm{b}}$, Bouzid Wassila ${ }^{\mathrm{a}}$ \\ ${ }^{a}$ Unité de Génie de Production Mécanique et Matériaux, ENIS, Route Soukra Km 3,5-B.P. 1173-3038, Sfax, Tunisia \\ ${ }^{\mathrm{b}}$ Université de Toulouse, INPT/ENIT, Laboratoire Génie de Production, 47 avenue d'Azereix, BP 1629, F-65016, Tarbes Cedex, France
}

A R T I C L E I N F O

Keywords:

Ball-end milling

Runout

Cutter workpiece engagement region

Chip thickness

Cutting forces

\begin{abstract}
A B S T R A C T
In order to obtain desired surface quality, the machining parameters such as feed per tooth, spindle speed, axial and radial depth of cut have been selected appropriately by using a process model. The surface quality and the process stability are related to cutting forces which are more influenced by the instantaneous chip thickness and the cutter-workpiece engagement (CWE) region. To reach a high accuracy in cutting forces calculation it is primary to determinate the start and the exit angles on the (CWE) region. Unlike previous studies which calculated the (CWE) numerically. This paper proposes an analytical model to calculate the (CWE) region by determining the cutting instantaneous flute entry and exit angles. These locations are calculated according to the heights of axial depth of cut. The second proposed approach is to calculate the instantaneous undeformed chip thickness. These solutions are used to calculate accurately the cutting forces in the case of the 3 axis milling operations.
\end{abstract}

To validate the model, a mechanistic cutting forces model was simulated and compared to the measured one. A good agreement between them was proved.

\section{Introduction}

The goal of the virtual simulation is to aid the producer to choose the adequate machining parameters before the realization of the parts on the machine tools. These parameters are chosen according to the imposed quality criteria. The most important criterion is the topography of the machined surface; it is influenced by the flexion and vibrations phenomena resulting from the cutting forces.

The cutting forces modeling gains more importance in order to prevent excessive cutter deflection and surface errors in milling process. Its prediction is not easy because of the difficulty to control the cutting geometries during machining. In fact, it is important to determinate the instantaneous flute enter and exit angles, this information help to know the exact value of the instantaneous chip thickness and the cutting length which are the two fundamental parameters in the determination of the cutting forces from mechanistic models.

In the previous works, some researchers have been interested in the calculation of the (CWE) region. Ju et al. [1] proposed a discrete boundary representation based on the exact Boolean method to calculate the (CWE) at every cutter location. Zhiyang [2] proposed a method based on the tessellated format. The CAD surface model is stored in tessellated format as an STL file which is transformed in a very large number of triangular facets. The algorithm finds the intersection curves form one or multiple closed regions on the ball end mill which forms the (CWE) regions. Boz et al. [3] compared two models for (CWE) calculations. The first method is a discrete model which uses three-orthogonal dexelfield and the second method is a solid modeler based model using parasolid boundary representation kernel. The second method was proved more accurate. In the study of Kiswanto et al. [4], the (CWE) region is determined by finding the length of each cut at every engagement angle between the lower engagement (LE) point and the upper engagement (UE) point and the swept envelope of the removed volume. Ozturk and Lazoglu [5] proposed a numerical method to determine the chip load of a ball-end mill during free-form machining. The chip load was obtained by defining three engagement boundaries: the tool entry boundary, the exit boundary and the workpiece surface boundary.

Iwabe et al. [6] calculated the chip area of the inclined surface machined by ball end mill cutter by a contour path method using 3DCAD. The chip area is calculated by the interference of the rake surface and the chip volume. Sato et al. [7] calculated the (CWE) region based on the geometric tool-workpiece intersection in order to predict the topography and surface roughness as a function of cutting parameters. The geometric model is presented in the case of a flat surface machined

\footnotetext{
* Corresponding author.

E-mail address: lotfi_sai@yahoo.com (S. Lotfi).
} 


\author{
Nomenclature \\ $P \quad$ Point in the intersection between the cutter and the \\ workpiece \\ $R_{W} \quad$ Coordinate system attached to the workpiece \\ $R_{H} \quad$ Coordinate system attached to the spindle \\ $R_{C} \quad$ Coordinate system attached to the center of the cutter \\ $e \quad$ Runout error (mm), offset distance between $Z H$ axis and \\ $Z C$ axis \\ $\rho \quad$ The initial eccentricity angle $\left({ }^{\circ}\right)$, measured at $t=0$, be- \\ tween $Y C$ axis and $Y H$ axis \\ $a_{e} \quad$ Radial depth of cut (mm) \\ $a_{p} \quad$ Axial depth of cut (mm) \\ $f_{z} \quad$ Feed per tooth per revolution ( $\mathrm{mm} /$ tooth/rev) \\ $P_{r} \quad$ Plane defined perpendicular to the tool axis $Z C$, contains \\ $Y C$ and $Y H$ axis \\ $P_{a e} \quad$ Plane perpendicular to the plane $P r$, contains cross feed \\ direction and $\mathrm{Z}_{\mathrm{C}}$ axis \\ $P_{f z} \quad$ Plane perpendicular to the plane $P r$, contains feed direc- \\ tion and $\mathrm{Z}_{\mathrm{C}}$ axis \\ $z \quad$ The local height of point $P$ \\ $i_{0} \quad$ Tool Helix angle $\left({ }^{\circ}\right)$ \\ $\theta \quad$ revolution angle $\left({ }^{\circ}\right)$ \\ $\varphi(z) \quad$ Locating angle of point $P$ measured in $\operatorname{Pr}$ plane between
}

$\mathrm{O}_{\mathrm{C}} \mathrm{P}$ and $\mathrm{X}_{\mathrm{C}}$ axis $\left({ }^{\circ}\right)$

$z \quad$ Local height of point $P(\mathrm{~mm})$

$R_{O} \quad$ The tool radius (mm)

$R(z) \quad$ The local circumference radius of point $P$, distance of point $P$ to axis $Z C(\mathrm{~mm})$

$\psi \quad$ The included angle between $O C P$ and $Z C$ axis $\left({ }^{\circ}\right)$

$t \quad$ The instant time $(s)$

$V_{f} \quad$ Feed rate $(\mathrm{mm} / \mathrm{min})$

$w \quad$ Spindle speed (rd/s)

$N \quad$ Spindle speed (rev/min)

$N_{f} \quad$ Number of teeth

Ost Start angle in the cutter-workpiece engagement region $\left(^{\circ}\right)$

$\theta_{E x} \quad$ Exit angle in the cutter-workpiece engagement region $\left({ }^{\circ}\right)$

$t_{n} \quad$ Instantaneous undeformed chip thickness $(\mathrm{mm})$

$\mathrm{db} \quad$ Infinitesimal chip width $(\mathrm{mm})$

$d S \quad$ The infinitesimal length of cutting edge $(\mathrm{mm})$

$k_{t o} k_{r o} k_{a c}$ Tangential, radial and axial cutting force coefficient $(\mathrm{N} /$ mm2)

$k_{t e}, k_{r e}, k_{a e}$ Tangential, radial and axial cutting edge coefficient ( $N$ / $\mathrm{mm}$ )

$d F_{b} d F_{n}, d F_{a}$ The differential cutting forces in tangential, radial and axial direction $(N)$

$F_{x}, F_{y}, F_{z}$ The cutting forces respectively in $X, Y$ and $Z$ direction (N) by a ball end mill on one way strategy. Another phenomenon which influences the (CWE) region and the chip thickness and is not considered in this study is the motion errors of feed drive systems. Then, Nishio et al. [8] investigated the influence of dynamic motion errors of feed drive systems onto the surface machined by a square end mill.

In the study of Erdim et al. [9], the (CWE) is calculated from the output Cutter Location data file by an analytical simulation. Gong et al. [10] determined the (CWE) using a triangle mesh model and the intersection calculations of the cutter swept volume. Ozturk et al. [11] and Erdim and Sullivan [12] calculated the (CWE) by subtracting it from the swept volume of tool motion. The tool is divided into elementary disks and the engagement points are extracted, then the start and exit angles are calculated.

Sun et al. [13] calculated the (CWE) using a Z-map model. The workpiece is meshed into small grids whose projection onto the $x-y$ plane is a square. The engaged cutter element can be achieved according to the difference between the cutter element and the projection of the instantaneous workpiece height into the cutter element.

Boz et al. [14] used a B-rep modeler to calculate the (CWE). In the study of Mamedov and Lazoglu [15] a method based on solid modelers was employed in which the (CWE) was calculated at each cutter location point. From the cutter location file, the swept volume of the tool was calculated and subtracted from a blank workpiece. After subtraction, the start and exit angles of each discretized cutting disc were calculated.

The approximation proposed by Zeroudi et al. [16], calculates the (CWE) as a region delimited by three boundaries. The first was the relative position of the workpiece uncut surfaces. The second was the previous tool path considered without any tool deflection and with perfect surface finishes and has a cylindrical form. The third was the path of the previous tooth considered as a circular path. An analytical model was proposed by Sai et al. [17], where the cutter runout error was neglected.

The (CWE) zone between the tool and the machined part represents the integration limits used in the calculation of the cutting forces. The instantaneous cutting chip thickness can also be modeled correctly by knowing the area of engagement between the part and the tool. The validation of these models requires the modeling of the cutting forces. In the mechanistic method, cutting forces are assumed proportional to the uncut chip thickness or cutter swept volume.

Yucesan and Altıntaş [18] proposed a ball-end mill forces model based on a mechanistic relationship between cutting forces and chip load. This model discretizes the ball-end mill into a series of disks and describes in fairly rigorous detail the ball-end mill geometry and chip thickness calculation. In the study of Ko and Cho [19] the dynamic effect is considered in the chip thickness model. For more accuracy in the prediction of the cutting forces, Altintas and Lee [20] proposed a mechanistic cutting forces model for 3D ball-end milling using instantaneous cutting forces coefficients. These coefficients are independent of the cutting conditions and are set as a function of the instantaneous uncut chip thickness only. They consider the size effect produced near the tool tip at the low values of undeformed chip thickness.

Liu et al. [26] proposed a theoretical dynamic cutting forces model for ball-end milling using the integrated method. The elementary cutting forces components are integrated using the slices elements of the flute along the cutter-axis direction. The size effect of undeformed chip thickness and the influence of the effective rake angle are considered in the formulation of the differential cutting forces based on the theory of oblique cutting.

Cheng [27] studied the influences of tool the wear, the tool breakage and the vibrations in the machining process which increase the cutting forces and causes a poor surface roughness.

In this paper, the models of the instantaneous chip thickness and the (CWE) zone is developed for the calculation of the cutting forces for flat surfaces perpendicular to the tool axis and considering the runout error. The content is presented in the following section as follows: First, the geometrical description of the trajectory of an arbitrary point $\mathrm{P}$ in the (CWE) is presented in the local coordinate system attached to the center of the tool then in the local coordinate system attached to the spindle. Second, these coordinates are transformed to the global coordinate system attached to the workpiece. Third, based on the tooth trajectory and the geometry of the milled surface, the cutter workpiece engagement (CWE) is analyzed and the entrance and exit angles are extracted, then the instantaneous undeformed chip thickness is calculated. Finally, a simulation using Matlab software was proposed to predict the cutting forces based on a mechanistic approach.

The predicted forces are compared with the measured ones where 
they present a good agreement.

\section{General formulation of the coordinate system}

In this work, a ball nose end milling cutter with two teeth $N_{f}=2$, uniformly distributed was considered, $R_{O}$ is the cutter radius and $i_{O}$ is its helix angle. $\mathrm{P}\left(X_{P}, Y_{P}, Z_{P}\right)$ denotes intersection points between the cutter and the work-piece. The coordinate system is established in order to obtain the parametric equation of the point $\mathrm{P}$ in the global coordinate system $R_{W}$ attached to the workpiece.

$R_{W}\left(O_{W}, \vec{X}_{W}, \vec{Y}_{W}, \vec{Z}_{W}\right)$ : The global coordinate system attached to the workpiece in which the tool path is defined Fig. 3.

$R_{H}\left(O_{H}, \vec{X}_{H}, \vec{Y}_{H}, \vec{Z}_{H}\right)$ : The local coordinate system attached to the spindle of the mill machine. It moves in the direction of feed rate speed relative to the workpiece. $Z_{H}$ is the axis of the spindle and $O_{H}$ and $O c$ are in the plane $\left(P_{r}\right)$ perpendicular to the tool axis during milling process, Fig. 1.

$R_{C}\left(O_{C}, \vec{X}_{C}, \vec{Y}_{C}, \vec{Z}_{C}\right)$ : The local coordinate system fixed on the center of the cutter.

Considering initially at $t=0$, that $\overrightarrow{O_{H}} Y_{H}$ and the vector of cutter runout, $\vec{e}$, are aligned. In this position the initial eccentricity angle measured between $\overrightarrow{O_{C} Y}$ and $\overrightarrow{O_{H} Y}$ is $\rho$. When the cutter revolves around the spindle axis $\vec{O}_{H} Z_{H}$ by a rotate angle $\theta$, the total rotates angle between $\overrightarrow{O_{C} Y_{C}}$ and $\overrightarrow{O_{H} Y_{H}}$ Become $(\theta+\rho)$ as shown in Fig. 1 .

\section{Mathematical description of the trajectory of cutting edge}

The coordinates of a point $P$ on the $\mathrm{i}^{\text {th }}$ cutting edge in the local coordinate system $R_{C}\left(O_{C}, \vec{X}_{C}, \vec{Y}_{C}, \vec{Z}_{C}\right)$ as are shown in Fig. 1 are expressed by the Eq. (1) as (Fig. 2):

$\left.\overrightarrow{O_{C} P}\right|_{R c}=\left[\begin{array}{c}X_{P} \\ Y_{P} \\ Z_{P}\end{array}\right]_{R c}=\left[\begin{array}{l}R(z) \cos (\varphi(z)) \\ R(z) \sin (\varphi(z)) \\ R_{0}\left[1-\frac{\varphi(z)}{\tan \left(i_{0}\right)}\right]\end{array}\right]$

The different parameters $\varphi(z)$ and $R(z)$ are calculated as follows:

$\varphi(z)=\frac{z \tan \left(i_{0}\right)}{R_{0}}$ and $R(z)=\sqrt{2 R_{0} z-z^{2}}$

The position of the point $P$ is written in the coordinate system $R_{H}$ as:

$\left.\overrightarrow{O_{H}} P\right|_{R H}=\left[\begin{array}{c}X_{P} \\ Y_{P} \\ Z_{P}\end{array}\right]_{R H}=\left[\begin{array}{c}e \sin (\theta) \\ e \cos (\theta) \\ 0\end{array}\right]_{R_{H}}+M \quad\left[\begin{array}{l}R(z) \cos (\varphi(z)) \\ R(z) \sin (\varphi(z)) \\ R_{0}\left[1-\frac{\varphi(z)}{\tan \left(i_{0}\right)}\right]\end{array}\right]_{R c}$

Where $M_{C H}$ is the matrix transformation from $R_{C}\left(O_{C}, \vec{X}_{C}, \vec{Y}_{C}, \vec{Z}_{C}\right)$ to $R_{H}\left(O_{H}, \vec{X}_{H}, \vec{Y}_{H}, \vec{Z}_{H}\right)$.

$M_{C H}=\left[\begin{array}{ccc}\cos (\theta+\rho) & -\sin (\theta+\rho) & 0 \\ \sin (\theta+\rho) & \cos (\theta+\rho) & 0 \\ 0 & 0 & 1\end{array}\right]$

The coordinates of point $P$ in the global coordinate system attached to the workpiece $R_{W}\left(O_{W}, \vec{X}_{W}, \vec{Y}_{W}, \vec{Z}_{W}\right)$ are expressed by the Eq. (3):

$$
\begin{aligned}
\overrightarrow{\left.O_{W} P\right|_{R W}}= & {\left[\begin{array}{c}
X_{P} \\
Y_{P} \\
Z_{P}
\end{array}\right]_{R W}=\left[\begin{array}{c}
X_{O H} \\
Y_{O H} \\
Z_{O H}
\end{array}\right]_{R W} } \\
& +\left[\begin{array}{c}
e \sin (\theta) \\
e \cos (\theta) \\
0
\end{array}\right]_{R_{H}}+M \quad\left[\begin{array}{l}
R(z) \cos (\varphi(z)) \\
R(z) \sin (\varphi(z)) \\
R_{0}\left[1-\frac{\varphi(z)}{\tan \left(i_{0}\right)}\right]
\end{array}\right]_{R c}
\end{aligned}
$$

Where: $X_{O H}, Y_{O H}$ and $Z_{O H}$ are the coordinates of point $O_{H}$ in the global coordinate system $R_{W}$.

The Eq. (3) can be developed as:
$\left\{\begin{array}{c}X_{p}=X_{O H}+e \sin (\theta)+R(z) \sin (\theta+\rho-\varphi(z)) \\ Y_{p}=Y_{O H}+e \cos (\theta)+R(z) \cos (\theta+\rho-\varphi(z)) \\ Z_{p}=Z_{O H}+R_{0}\left[1-\frac{\varphi(z)}{\tan \left(i_{0}\right)}\right]\end{array}\right.$

In this paper the study considers the one way machining strategy where the feed rate is in $X$ axis direction, the cross feed is in $Y$ axis direction. For these hypotheses the Eq. (4) of the trajectory of point $P$ in the global coordinate system $R_{W}$ can be written as Eq. (5):

$\left\{\begin{array}{c}X_{p}=V_{f} t+e \sin (w t)+R(z) \sin (w t+\rho-\varphi(z)) \\ Y_{p}=e \cos (w t)+R(z) \cos (w t+\rho-\varphi(z)) \\ Z_{p}=R_{0}\left[1-\frac{\varphi(z)}{\tan \left(i_{0}\right)}\right]\end{array}\right.$

Where $t$ is the instant time and $V_{f}$ is the feedrate

\section{Cutter / workpiece engagement region in ball end milling process}

The (CWE) determination is not easy in ball end milling. The engagement region for any elementary disc is bounded between the start and exit angles which changes according to the local height of elementary disc. Fig. 3 shows the representation of the different (CWE) zones and the planes in a 3D view used in the next step to define different geometrical parameters. In ball end milling process, the tooth feed is kept to comparably less than the radial depth of cut. In general the ratio feed/radial depth $\left(f_{z} / a_{e}\right)$ is less than one third. The radial depth of cut $a_{e}$ is considered bigger than the feed per tooth $f_{z}$.

To calculate the entry and the exit angles for any elementary disc, it is necessary to determine the trajectory of the point $P$, the intersection of this disc and the workpiece. Examining the trajectories of the different points $P$ for the $(i+1)^{\text {th }}$ tool path for each local height $z$, as shown in the Fig. 4-a. we can distinguish three configurations detailed in Fig. 4-b--d.

The first configuration is when the teeth do not make a complete rotation in contact with the material and exit on surfaces generated by the (i) ${ }^{\text {th }}$ tool path, this upper part is noted zone-I and its form of trajectory is presented in Fig. 4-b. The second is when the teeth make a complete rotation in contact with the workpiece noted zone-II. We distinguish in lower part two configurations that can be noted zone-II-1 and zone-II-2. Their forms of trajectories are presented respectively in Fig. 4-c and -d. So the (CWE) region can be divided into three zones. The first is represented in the plane $\left(P_{a e}\right)$ defined by the cross feed direction and the $Z_{C}$ axis of the tool, as shown in Fig. 5. The second and the third are represented in the plane $\left(P_{f z}\right)$ defined by the feed direction and the $Z_{C}$ axis of the tool as shown in Fig. 6 .

Based on Figs. 5 and 6, the zone-I is the region for $2 R(z) \geq a_{e}$ and the zone-II is for $2 R(z)<a_{e}$. The zone-II is then divided into two zones. The zone-II- 1 is the region for $f_{z} \leq 2 R(z)<a_{e}$ and the zone-II- 2 is for $2 R$

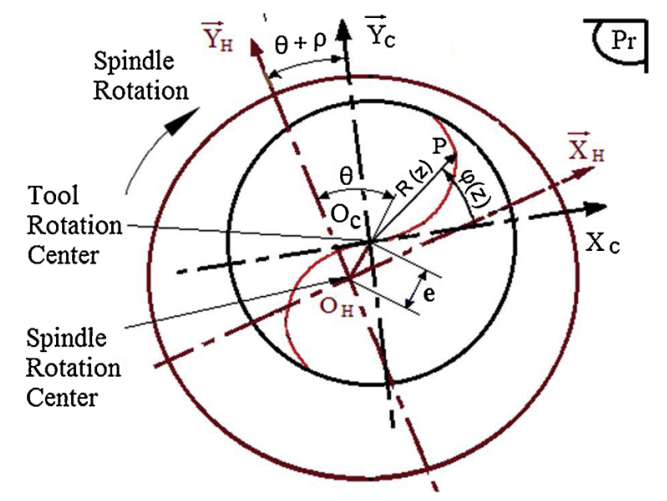

Fig. 1. Location of point $P$ on the cutting edge view in plane $P_{r}$. 


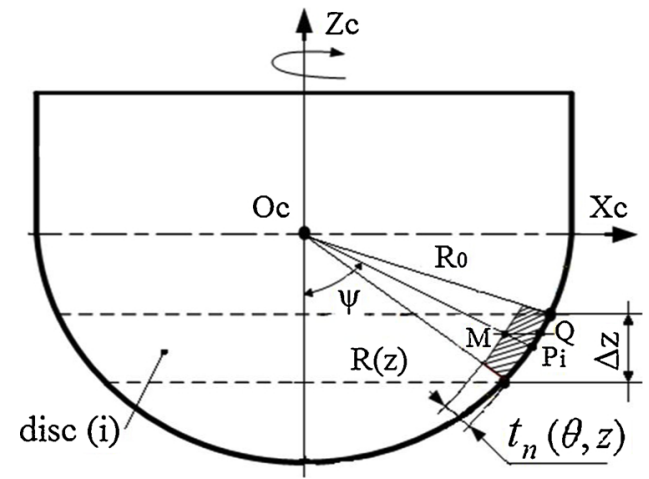

Fig. 2. Location of point $P$ in coordinate system attached to the tool view in plane $P_{a e}$.

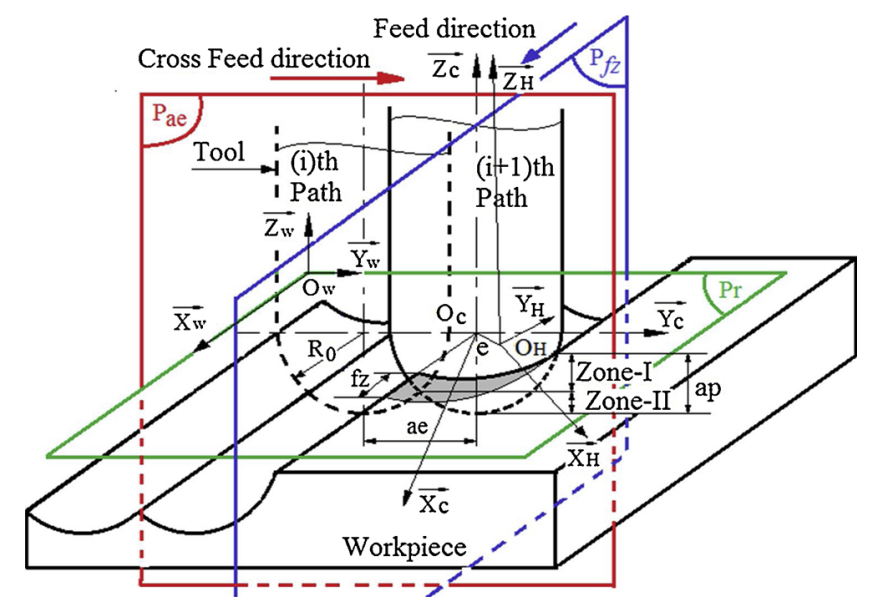

Fig. 3. (CWE) region and different planes representation in 3D view.

$(z)<f_{z}$ as is shown in the view in the plane $\left(P_{f z}\right)$. Each zone in the (CWE) region can be identified in $Z_{C}$ axis direction by its local height $z$ as Eq. (6):

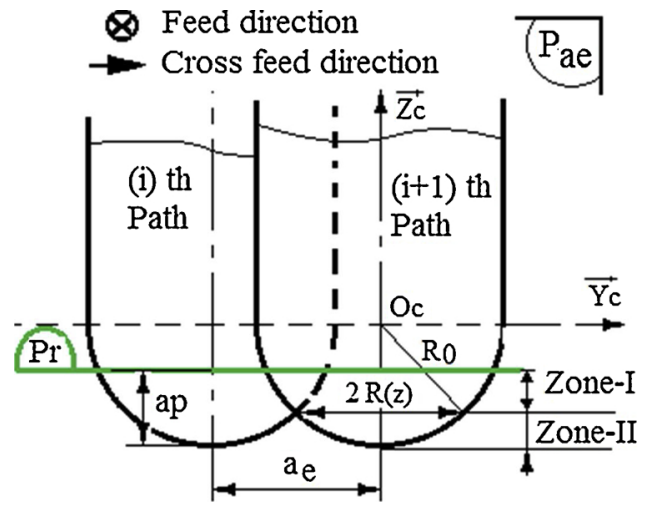

Fig. 5. (CWE) region Zone-I and Zone-II, view in plane $P_{a e}$.

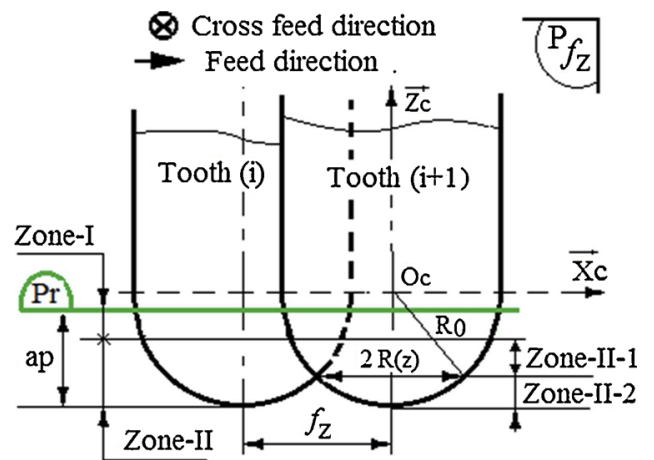

Fig. 6. (CWE) region Zone-II-1 and Zone-II-2, view in plane $P_{f z}$.
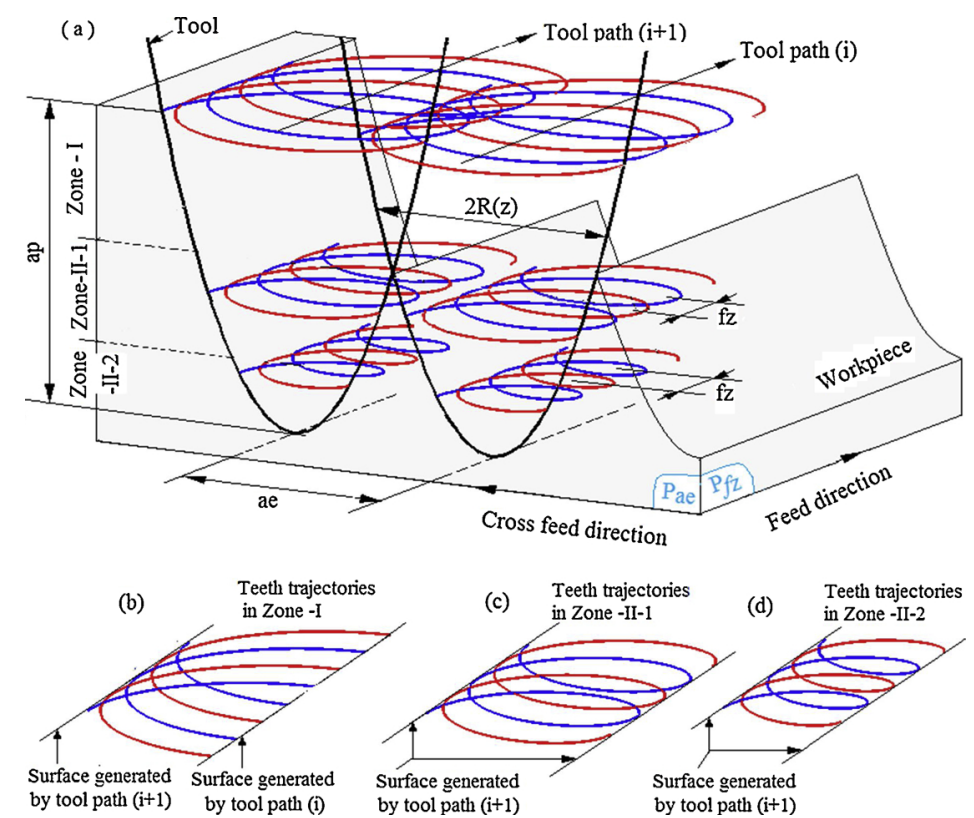

Fig. 4. Teeth trajectories configurations in three zones, (a): CWE zones, (b): teeth trajectories in zone-I, (c): teeth trajectories in zone-II-1, (d): teeth trajectories in zone-II-2. 


\subsection{The engagement zone-I}

In the plane view $\left(P_{r}\right)$, the distance between the initial and final workpiece curves is the radial depth of cut $a_{e}$. This region represents the material removed for one pass. The zone-I is the region, where the point $P$ in the cutting-edge exits on the initial workpiece curve as is shown in Fig. 7. The produced chip is represented by the $A_{0} B C$ area. The curves $A_{0} B$ and $A_{0} C$ are two successive teeth trajectories. The points $B$ and $C$ are respectively exit points of the tooth $(i)$ and $(i+1)$ at a distance of instantaneous feed per tooth $f_{z}$. The entry and exit angles corresponding to $(i+1)^{\text {th }}$ teeth trajectories are respectively expressed as follows:

$\theta_{S t}(z)=-\cos ^{-1}\left(1-\frac{S_{h 1}(z)}{R(z)}\right), \theta_{E X}(z)=\cos ^{-1}\left(1-a_{e} / R(z)\right)$

The calculation of the start angle needs the determination of the distance $S_{h 1}$.

For determining the exact distance $S h_{k}(z)$, the coordinates of the point $A_{k}$ in the cutter workpiece engagement region must be known first. The start point $A_{k}$ at $\theta_{S t}$ start angle of the tooth verifies the Eq. (8) of the trajectory.

$X_{A k}\left(t_{k}\right)=V_{f} t_{k}+e \sin \left(w t_{k}\right)+R(z) \sin \left(w t_{k}+\rho-\varphi(z)\right)=(2 k+1) \frac{f_{z}}{2}$

$Y_{A k}\left(t_{k}\right)=e \cos \left(w t_{k}\right)+R(z) \cos \left(w t_{k}+\rho-\varphi(z)\right)$

Where $V_{f}$ is the feed rate, $t_{k}$ is the instant time, $k$ is the index of the entrance point $A_{k}$, the distance $S_{h k}(z)$ at point $A_{k}$ as shown in Fig. 8 is expressed by Eq. (9):

$S_{h k}(z)=R(z)-Y_{A k}\left(t_{k}\right)=R(z)\left(1-\cos \left(w t_{k}+\rho-\varphi(z)\right)\right)-e \cos \left(w t_{k}\right)$

For the elementary discretized disc with an effective radius $R(z)$, the only unknown in this equation is the instant time $t_{k}$ which must be determined through the Eq. (8-1) which can be written as Eq. (10):

$V_{f} t_{k}+e \sin \left(w t_{k}\right)+R(z) \sin \left(w t_{k}+\rho-\varphi(z)\right)=(2 k+1) \frac{f_{z}}{2}$

The determination of the distance $S_{h 1}(z)$ needs the determination of the coordinates of point $A_{o}$ correspond to the entrance angle $\theta_{S t}$ as shown in figure, at $X\left(A_{0}\right)=f_{z} / 2$ the instant time $t_{0}$ corresponding to this intersection is the solution of the Eq. 11 .

$V_{f} t_{0}+e \sin \left(w t_{0}\right)+R(z) \sin \left(w t_{0}+\rho-\varphi(z)\right)=\frac{f_{z}}{2}$

The solution of this equation $t_{0}$ is subsequently used to determinate the coordinate $Y\left(A_{0}\right)$, the distance $S h_{1}(z)$, the start and exit angles are determined by Eq. (7).

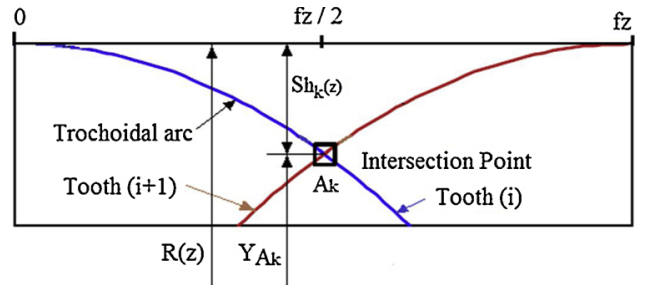

Fig. 8. Representation of the distance $S_{h k}(z)$ and entrance point $A_{k}$.

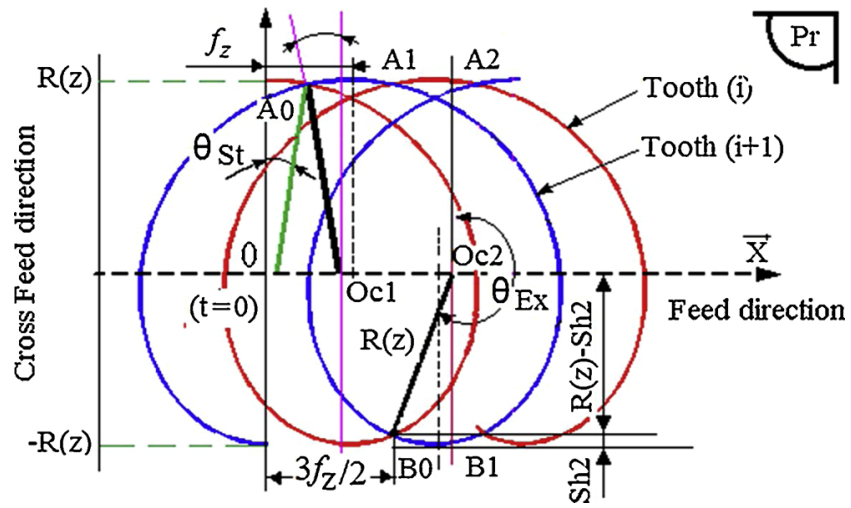

Fig. 9. Start and exit angles of the engagement region (Zone -II-1).

\subsection{The engagement Zone-II-1}

The trajectory of the point $P$ in the engagement Zone-II-1 is shown in Fig. 9. This zone is characterized by the condition $f_{z} \leq 2 R(z)<a_{e}$. The start angle is calculated as in the zone-I. The exit angle is calculated when the tooth $(i+1)$ reached the position of point $B_{0}$. The instant $t_{1}$ is calculated by the resolution of the Eq. (10) for $k=1$. The traveled distance by the tooth $(i+1)$ from zero to exit point $B_{0}$ in $X$ direction is $X$ $(t)=3 f_{z} / 2$. The tooth passes three times by the $X$ coordinates equal to $3 f_{z} / 2$ Fig. 9. The point $B_{0}$ corresponds to the second passage at time $t_{1}$. When the time $t_{1}$ is known, the distance $S_{h 2}$ is calculated and the exit angle is calculated. The start and exit angles are expressed by the Eq. (12).

$\theta_{S t}(z)=-\cos ^{-1}\left(1-\frac{S_{h 1}(z)}{R(z)}\right), \theta_{E X}(z)=\pi+\cos ^{-1}\left(1-S_{h 2}(z) / R(z)\right)$

The intersection of the two teeth trajectories is at the point $B_{O}$ as shown in Fig. 9, at $X\left(B_{0}\right)=3 f_{z} / 2$ the instant time $t_{1}$ corresponding to this intersection is the solution of the Eq. (13)

$V_{f} t_{1}+e \sin \left(w t_{1}\right)+R(z) \sin \left(w t_{1}+\rho-\varphi(z)\right)=\frac{3 f_{z}}{2}$

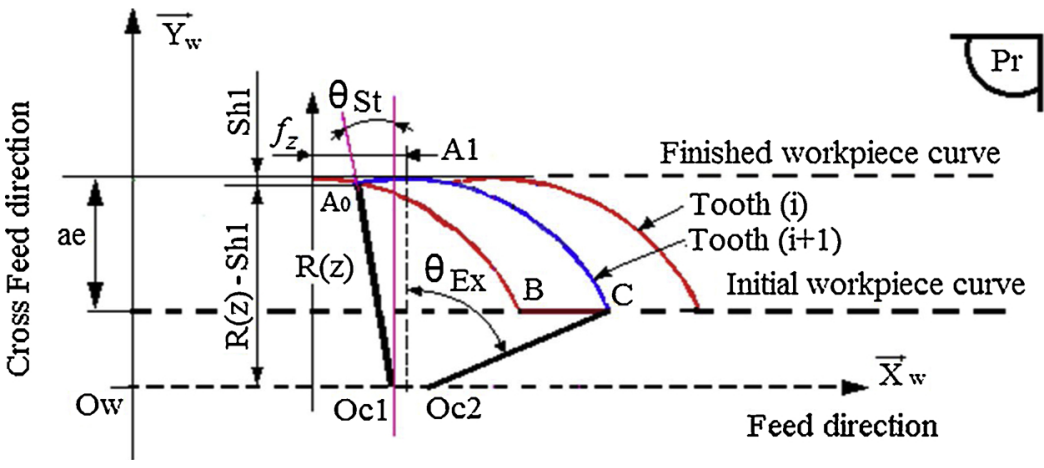

Fig. 7. Teeth trajectories, start and exit angles in the Zone-I. 
The solution of this equation is next used to determinate the coordinate $Y\left(B_{0}\right)$, the distance $S_{h k}(z)$ and the exit angle.

\subsection{The engagement zone-II-2}

The point $P$ on the (CWE) region Zone-II-2 rotates and does not intersect in the previous cutting tooth trajectory at the exit point as is shown in Fig. 10. The zone II-2 is characterized by the condition $\left(0 \leq 2 R(z)<f_{z}\right)$. The start angle is calculated for instant time $t_{0}$ when the tooth $(i+1)$ travels a distance $X(t)=f_{z} / 2$ at point $A_{o}$ as was developed previously. The exit angle is calculated for the instant $t_{2}$ at point $C_{1}$ when the tooth $(i+1)$ travels a distance equal to $2 f_{z}$. The instant $t_{2}$ is the solution of the Eq. (14) for the second pass of the tooth $(i+1)$ from point $C_{1}$.

$V_{f} t_{2}+e \sin \left(w t_{2}\right)+R(z) \sin \left(w t_{2}+\rho-\varphi(z)\right)=2 f_{z}$

When the instant $t_{2}$ and the distance $S_{h 3}$ are known, the exit angle can be calculated. The entry and exit angles are respectively expressed as follows Eq. (15):

$\theta_{S t}(z)=-\cos ^{-1}\left(1-S_{h 1}(z) / R(z)\right), \theta_{E X}(z)=2 \pi-\cos ^{-1}\left(1-S_{h 3}(z) / R(z)\right)$

In ball end milling process, the (CWE) region varies along the cutter axis. The engagement region is calculated between the lower and the higher elementary discs in contact on the workpiece and for each discretized disc, between the start and exit angle. The Fig. 11 shows the variation of the start and the exit angles. For the same immersion depth, the engagement region is larger when the radial depth increases. In the same radial depth of cut, the engagement region increases when the immersion depth decreases.

\section{Cutting forces model}

The real tooth motion is trochoidal, resulting from rotational motion of the spindle and the translational motion of the work piece. The calculation of the instantaneous undeformed chip thickness is based on the mathematical relationship between the tooth paths generated by different teeth on one milling cutter. The chip thickness for a tooth engaged in cutting $(i+1)$ is determined through finding the intersection point of the path curve left by the preceding tooth ( $i$ ) and the line passing throuter axis $C$, Sai et al. [21] (Fig. 12).

The instantaneous chip thickness $t_{n}$ is calculated for any elementary disc of the cutter. The position in $Z$ direction of the point $P$ between the tooth and the workpiece is constant and the position in $X Y$ plane change. To determinate $t_{n}$ it is important to know the distance $M Q$ first. When the tip of the tooth No ( $i)$ reaches the position of point $M\left(X_{M}, Y_{M}\right.$ $Z_{M}$ ) the angular position at instant $t_{1}$ is equal to $\theta_{M}$, the location of point $M$ can be determined from Eq. (16):

$\left\{\begin{array}{c}X_{M}(\theta, z)=V_{f} t_{1}+e \sin \left(\theta_{M}\right)+R(z) \operatorname{Sin}\left(\theta_{M}+\rho-\varphi(z)\right) \\ Y_{M}(\theta, z)=e \cos \left(\theta_{M}\right)+R(z) \operatorname{Cos}\left(\theta_{M}+\rho-\varphi(z)\right)\end{array}\right.$

The center of the cutter is located at the position of point $C$, determined from Eq. (17)

$\left\{\begin{array}{c}X_{C}(\theta, z)=V_{f} t_{2} \\ Y_{C}(\theta, z)=0\end{array}\right.$

When the tip of the tooth No $(i+1)$ reaches the position of point $Q$ $\left(X_{Q}, Y_{Q}, Z_{Q}\right)$ the angular position at instant $t_{2}$ is equal to $\theta_{Q}$, the location of point $Q$ can be determined from Eq.(18):

$\left\{\begin{array}{c}X_{Q}(\theta, z)=V_{f} t_{2}+e \sin \left(\theta_{Q}\right)+R(z) \operatorname{Sin}\left(\theta_{Q}+\rho-\varphi(z)\right) \\ Y_{Q}(\theta, z)=e \cos \left(\theta_{Q}\right)+R(z) \operatorname{Cos}\left(\theta_{Q}+\rho-\varphi(z)\right)\end{array}\right.$

Points $C, M$ and $Q$ are located on the same line; $\overrightarrow{C Q} \Lambda \overrightarrow{C M}=0$ the following equation can be obtained.
$\left(X_{Q}(\theta, z)-X_{C}(\theta, z)\right) Y_{M}(\theta, z)-Y_{Q}(\theta, z)\left(X_{M}(\theta, z)-X_{C}(\theta, z)\right)=0$

The angular position of points $M$ and $Q$ are respectively: $\theta_{M}=w t_{1}$, and $\theta_{Q}=w t_{2}-\pi$.

The Eq. (19) can be developed and expressed by Eq.(20):

$$
\begin{aligned}
& \left(e^{2}+R_{Z}^{2}+2 e R_{Z} \cos (\rho-\varphi(z))\right) \sin \left(\theta_{Q}-\theta_{M}\right) \\
& \quad+\frac{V_{f}\left(\theta_{Q}-\theta_{M}+\pi\right)\left(e \cos \left(\theta_{M}\right)+R_{Z} \cos \left(\theta_{M}+\rho-\varphi(z)\right)\right)}{w}=0
\end{aligned}
$$

The only unknown in Eq. (20) is $\theta_{Q}$ when it was determined, the position of point $Q$ expressed by Eq. (18) can be determined. The distance $M Q$ was determined and the instantaneous chip thickness can be determined from Eq. (21):

$$
\begin{aligned}
t_{n}(\theta, z) & =\|\overrightarrow{M Q}\| \sin (\psi(z)) \\
& =\sqrt{\left(X_{Q}(\theta, z)-X_{M}(\theta, z)\right)^{2}+\left(Y_{Q}(\theta, z)-Y_{M}(\theta, z)\right)^{2}}
\end{aligned}
$$

The difference $\left(\theta_{Q^{-}} \theta_{M}\right)$ can be regarded as an infinitesimal value. The value of $\sin \left(\theta_{Q^{-}} \theta_{M}\right)$ can be expanded as a Taylor's series: $\sin \left(\theta_{Q}-\theta_{M}\right)=\left(\theta_{Q}-\theta_{M}\right)-\frac{\left(\theta_{Q}-\theta_{M}\right)^{3}}{3 !}+\ldots$ Reserving only the first order of the series, $\sin \left(\theta_{Q}-\theta_{M}\right)=\left(\theta_{Q}-\theta_{M}\right)$ The Eq. (24) can be written as:

$$
\begin{aligned}
\left(e^{2}+\right. & \left.R_{Z}^{2}+2 e R_{Z} \cos (\rho-\varphi(z))\right)\left(\theta_{Q}-\theta_{M}\right) \\
& +\frac{V_{f}\left(\theta_{Q}-\theta_{M}+\pi\right)\left(e \cos \left(\theta_{M}\right)+R_{Z} \cos \left(\theta_{M}+\rho-\varphi(z)\right)\right)}{w}=0
\end{aligned}
$$

The relation between $\theta_{Q}$ and $\theta_{M}$ is as:

$$
\begin{aligned}
\theta_{Q}= & \theta_{M} \\
& -\frac{60 f_{Z}\left(e \cos \left(\theta_{M}\right)+R_{Z} \cos \left(\theta_{M}+\rho-\varphi(z)\right)\right)}{e^{2}+R_{Z}^{2}+2 e R_{Z} \cos (\rho-\varphi(z))+\frac{60 f_{Z}\left(e \cos \left(\theta_{M}\right)+R_{Z} \cos \left(\theta_{M}+\rho-\varphi(z)\right)\right)}{\pi}}
\end{aligned}
$$

Noting that, $\theta_{S t}$ and $\theta_{E x}$ are respectively, the start and the exit angles in the (CWE) zone. The instantaneous undeformed chip thickness $t_{n}(\theta$, z) is expressed by Eq. (24).

$t_{n}(\theta, z)=\left\{\begin{array}{c}t_{n}(\theta, z) \quad \theta_{S t} \leq \theta \leq \theta_{E x}, 0 \leq z \leq a_{p} \\ 0 \text { else }\end{array}\right.$

The chip width of cut $d b(z)$ corresponding to the elementary cutting edge is expressed by Eq. (25), the zenith angle $\psi(z)$ is defined between the tool axis $Z c$ and the position of the point $P$. the point $P$ in the middle of the elementary cutting edge as studied by Lee and Altintas [23] and Baburaj et al. [28].

$d b(z)=\Delta z / \sin (\psi(z))$

The infinitesimal length of cutting edge $d S(z)$ is expressed by Salmi et al. [22] Eq. (26):

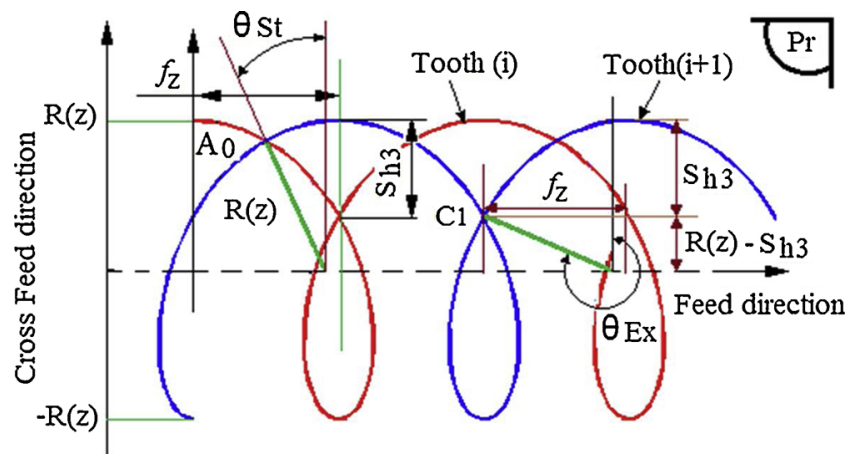

Fig. 10. Start and exit angle (Zone -II-2). 


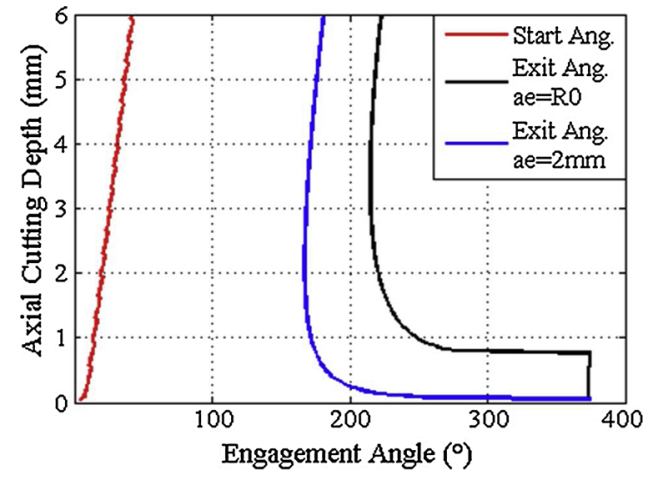

Fig. 11. Simulation of start and exit angle $R_{0}=6 \mathrm{~mm}, a_{p}=6 \mathrm{~mm}$, $f_{z}=0.5 \mathrm{~mm} /$ tooth $/ \mathrm{rev}$, without runout error.

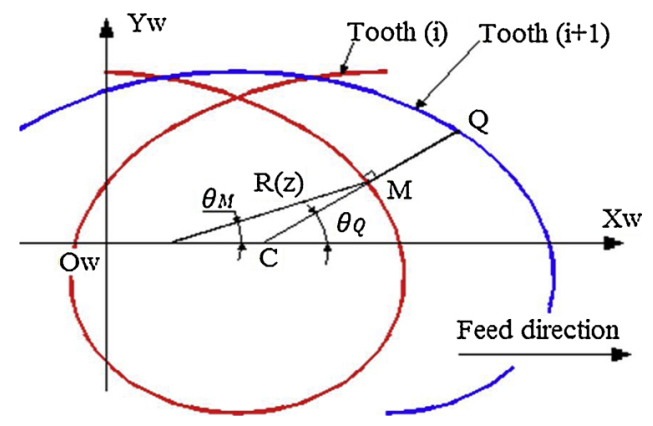

Fig. 12. Instantaneous undeformed chip thickness.

$d S(z)=d z\left[1+\frac{\left(R_{0}-z\left(1+\tan ^{2}\left(i_{0}\right)\right)\right)^{2}}{R(z)^{2}-z^{2} \tan ^{2}\left(i_{0}\right)}\right]^{1 / 2}$

For the engagement chip load in the engagement domain, the differential cutting force in radial, axial and tangential direction $(r, a, t)$ is written as Eq. (27). Lee and Alintas [23].

$$
\begin{aligned}
& d F_{t}(\theta, z)=k_{t e} d S(z)+k_{t c} t_{n}(\theta, z) d b(z) \\
& d F_{r}(\theta, z)=k_{r e} d S(z)+k_{r c} t_{n}(\theta, z) d b(z) \\
& d F_{a}(\theta, z)=k_{a e} d S(z)+k_{a c} t_{n}(\theta, z) d b(z)
\end{aligned}
$$

Where $k_{t e}, k_{r e}$ and $k_{a e}$ are the cutting edge coefficients $[\mathrm{N} / \mathrm{mm}] . k_{t c}$, $k_{r c}, k_{a c}$ are the tangential radial and axial cutting forces coefficients [N/ $\left.\mathrm{mm}^{2}\right]$. Cutting forces and edge coefficients are determined by a mechanistic calibration procedure. The transformation matrix $A$ transforms the cutting forces into the workpiece coordinate $R_{W}\left(O_{W}, \vec{X}_{W}, \vec{Y}_{W}, \vec{Z}_{W}\right)$ is expressed as Eq. (28):

$A=\left[\begin{array}{ccc}-\cos (\theta) & -\sin (\psi) \sin (\theta) & -\cos (\psi) \sin (\theta) \\ \sin (\theta) & -\sin (\psi) \cos (\theta) & -\cos (\psi) \cos (\theta) \\ 0 & \cos (\psi) & -\sin (\psi)\end{array}\right]$

The cutting forces in the workpiece coordinate which is also dynamometer coordinate is written as Eq. (29):

$$
\left[\begin{array}{l}
F_{x} \\
F_{y} \\
F_{z}
\end{array}\right]_{R w}=A \sum_{n=1}^{N f} \sum_{k=1}^{K}\left[\begin{array}{l}
d F_{t} \\
d F_{r} \\
d F_{a}
\end{array}\right]_{R c}
$$

\section{Experimental validation}

The workpiece material used in the experiments was the $42 \mathrm{CrMo} 4$ steel; the top surface is a circular part with diameter $100 \mathrm{~mm}$. It was divided on three areas as shown in Fig. 13-d, two lateral areas for the fixation on the Kistler dynamometer and the middle surface with size $82 \mathrm{~mm} \times 42 \mathrm{~mm}$ is prepared for the cutting tests.

The cutting tool used is a ball end mill coated by TiSiN with a diameter $R_{O}=5 \mathrm{~mm}$, two teeth $N_{f}=2$, the helix angle was $i_{O}=30^{\circ}$, the total length was $L=100 \mathrm{~mm}$ and the active length was $15 \mathrm{~mm}$ Fig. 13c. the cutter was traveled along a linear tool path. All cutting experiments were in up milling. The tests were conducted without cutting fluid. The machine used is a CNC HS Milling center HURON KX10, Fig. 13-a. Kistler 3-component dynamometer (model 9257B) was used for force data acquisition.

The test is used to validate the proposed method. The machining strategy is the one-way; the cutting parameters are: the cutting speed $V_{c}=745.7 \mathrm{~m} / \mathrm{min}$, the spindle speed $N=23,750.4 \mathrm{rev} / \mathrm{min}$, the feed rate $V_{f}=4750 \mathrm{~mm} / \mathrm{min}$, the radial depth of cut $a_{e}=1 \mathrm{~mm}$, the axial depth of cut $a_{p}=1 \mathrm{~mm}$, the feed per tooth $f_{z}=0.1 \mathrm{~mm} /$ tooth $/ \mathrm{rev}$, the runout error $e=6 \mu \mathrm{m}$ and the eccentricity angle $\rho=67^{\circ}$. The process is supposed rigid. The flexion of the tool and the vibrations are negligible.

The (CWE) region, the instantaneous chip thickness and the force simulations are all simulated with Matlab R2013b software. The (CWE) region is calculated and presented in the Fig. 14-a, for the tooth 1 and in the Fig. 14-b for the tooth 2. It represents the region which the cutter is engaged on the workpiece material per one revolution. This region is delimited by two limits represented by the start angle and the exit angle. As shown in Fig. 14-b, at the top surface of the part at $a_{p}=1 \mathrm{~mm}$ the higher height limit of the zone-I, the tooth attack the workpiece at rotational angle $0^{\circ}$ and exit at angle equal to $56^{\circ}$. The engagement angle becomes larger in lower limit of zone-I and reaches an angle of $180^{\circ}$ at $a_{p}=0.025 \mathrm{~mm}$. The contact is more important below and reaches $195^{\circ}$ in the lower height of the zone-II- 1 at $a_{p}=0.00025 \mathrm{~mm}$ and reaches $360^{\circ}$ at the end of the zone-II- 2 in the tool tip.

The cutter runout $e$ and the eccentricity angle $\rho$ are measured on the tooth 1 . Its equivalent rotational radius around the $Z_{H}$ axis is bigger than the initial one for the tooth 2 . The cutter workpiece engagement region is more important for the tooth 1 as shown in Fig. 14-a for the same local height in the $Z_{H}$ axis. The engagement angle is $62^{\circ}$ at $a_{p}=1 \mathrm{~mm}$, this difference influences in the next step the cutting forces for each tooth.

Based on the trocoidal tooth trajectory and the cutting parameters the engagement region is calculated and the instantaneous undeformed chip thickness is extracted. The value of the instantaneous undeformed
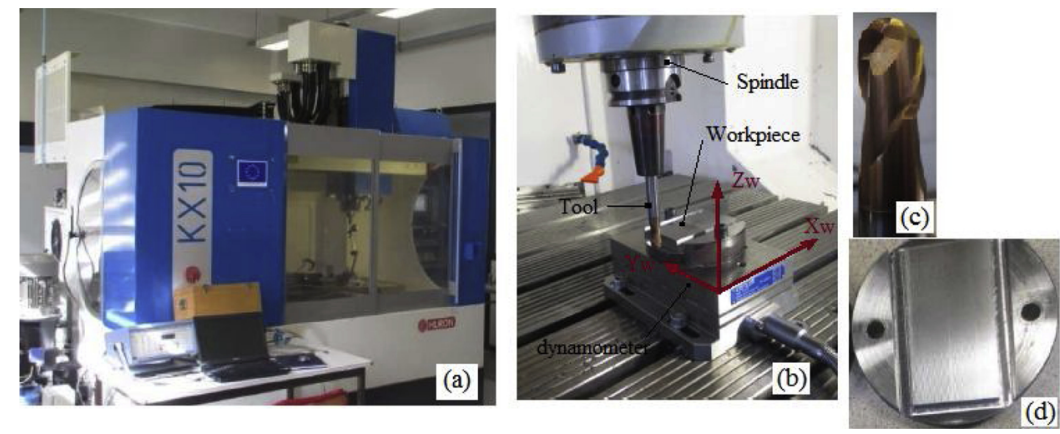

Fig. 13. (a) Milling machine (b) experimental setup, (c) ball end mill cutter (d) image of machined surface. 

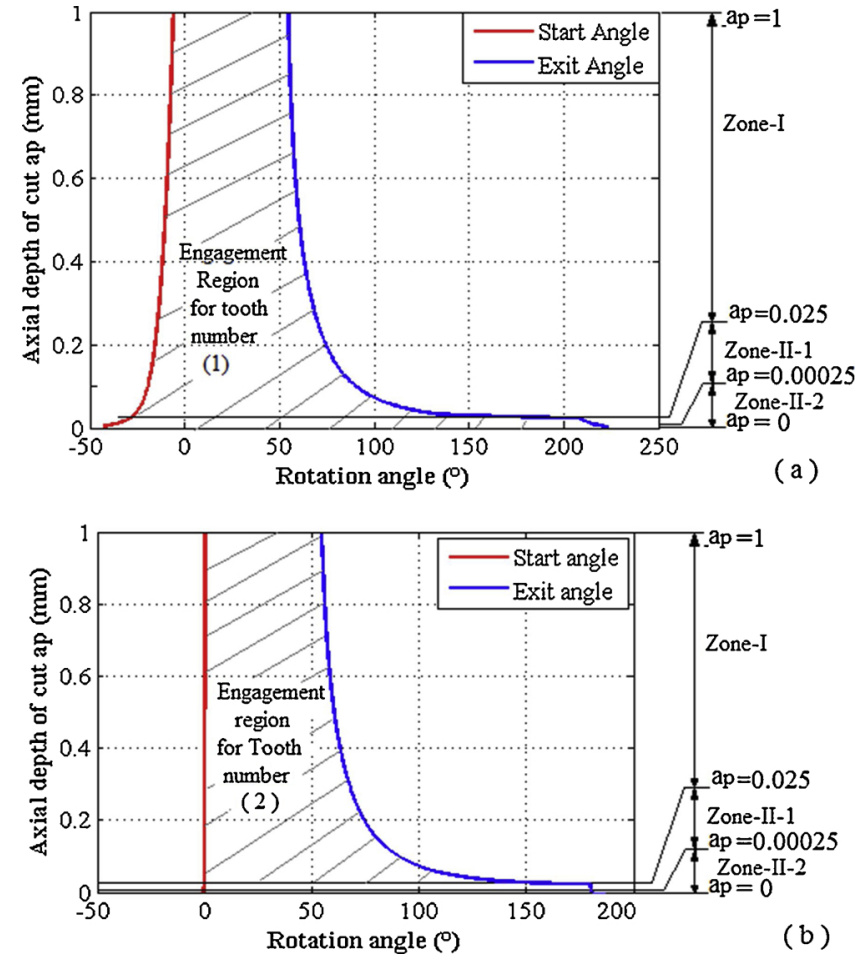

Fig. 14. (CWE) region representations start and exit angles, $N=23,750.4 \mathrm{rev} /$ min, $a_{e}=1 \mathrm{~mm}, a_{p}=1 \mathrm{~mm}, f_{z}=0.1 \mathrm{~mm} / \mathrm{tooth} / \mathrm{rev}$, (a): for first tooth on which the runout $e=6 \mu \mathrm{m}$ and the eccentricity angle $\rho=67^{\circ}$ is measured. (b): for the second tooth.

chip thickness for any position of elementary discretized discs on the axial depth of cut and for any engagement position is simulated and represented in the Fig. 15. It is clear that the runout influences the instantaneous chip thickness. The two teeth remove a chip with different thicknesses. The tooth number 1 removes a chip thickness which its maximum reached $0.1 \mathrm{~mm}$; the tooth number 2 removed a less chip thickness and reaches at its maximum $0.092 \mathrm{~mm}$. The uncut chip thickness produced by the two teeth is different in magnitude and in the rotational angle ranges. This difference is caused by the different rotational equivalent radii of each tooth induced by the cutter runout.

The cutting forces are simulated using the Eq. (29). The measured and predicted cutting forces with the proposed model for the investigated cutting conditions are shown in Figs. 16 and 17. The calibration coefficients $k_{t e}, k_{r e}, k_{a e}, k_{t c}, k_{r c}$, and $k_{a c}$ are obtained from an

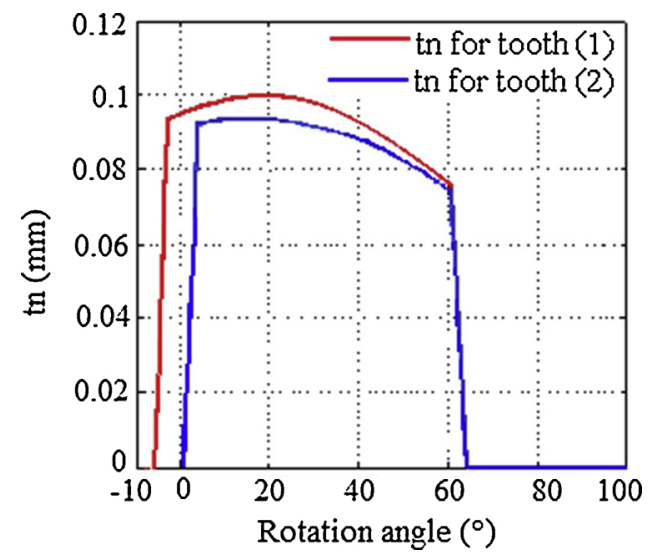

Fig. 15. Instantaneous chip thickness removed in the top of the machined surface, $N=23,750.4 \mathrm{rev} / \mathrm{min}, a_{e}=1 \mathrm{~mm}, a_{p}=1 \mathrm{~mm}, f_{z}=0.1 \mathrm{~mm} /$ tooth $/ \mathrm{rev}$, the runout measured on tooth (1) is $e=6 \mu \mathrm{m}$ and its eccentricity is $\rho=67^{\circ}$. horizontal slot cutting tests for different cutting parameters. The calibration coefficients method used in this study is presented by Ozturk et al. [24]. This method uses the calibration algorithm of Gusel and Lazoglu [25] which considers the start and exit angles of the slot cutting tests are respectively $0^{\circ}$ and $180^{\circ}$.

Figs. 16 and 17 show respectively, the measured and the simulation cutting forces with a cutter runout of $0.006 \mathrm{~mm}$ in the radial direction, the measurement setting and the simulation parameters are the same. Unequal cutting forces are loaded on the cutting edges. In the first period corresponding to the first cutting edge the magnitude of the cutting forces is greater according to the high value of the uncut chip thickness induced by the cutter runout. The cutting forces in the intermediate zone specified in detail (A) presents a non-zero value of the magnitude. This difference is due to the larger zones of the (CWE) region near the tool tip as was developed in the previous section.

In general a good agreement is observed between the predicted and the measured forces and it is illustrated in both shape and magnitude. The prediction errors defining as the difference between the absolute maximum value of measurement and prediction are partly due to residual instabilities that cannot be completely eliminated and are not taken into account in the rigid version of the model presented here. Since the model developed here considers the cutting tool as rigid, this error is due to tool deflections and vibrations. These two phenomena may contribute to the variations in the instantaneous chip thickness. The cutting edge is considered perfectly sharp in the model and in reality the material is sometimes pushed back or crushed and not removed, which generates parasite forces due to deformation material under the cutting edge.

The simulated cutting forces using the conventional methods are
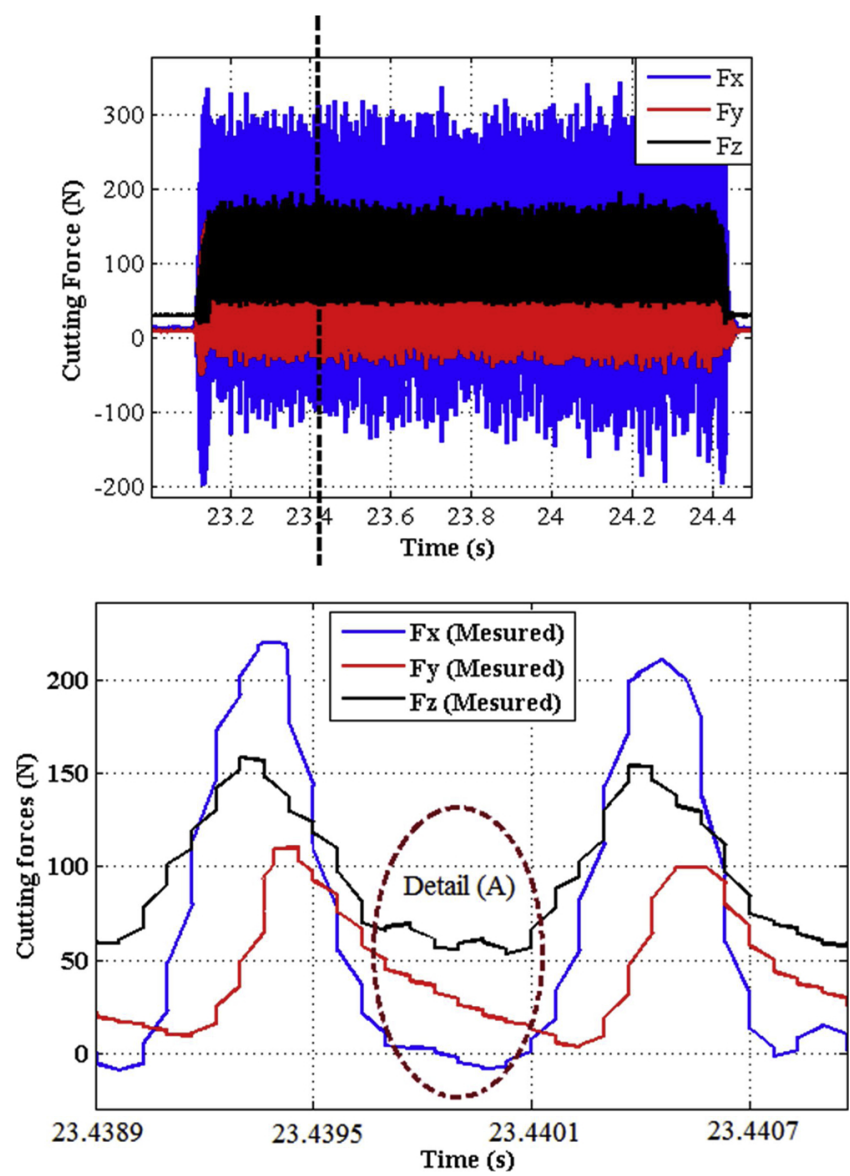

Fig. 16. Measured cutting forces, $N=23,750.4 \mathrm{rev} / \mathrm{min}, a_{e}=1 \mathrm{~mm}, a_{p}=1 \mathrm{~mm}$, $f_{z}=0.1 \mathrm{~mm} /$ tooth $/ \mathrm{rev}$, the runout measured on tooth (1) is $e=6 \mu \mathrm{m}$ and its eccentricity is $\rho=67^{\circ}$. 


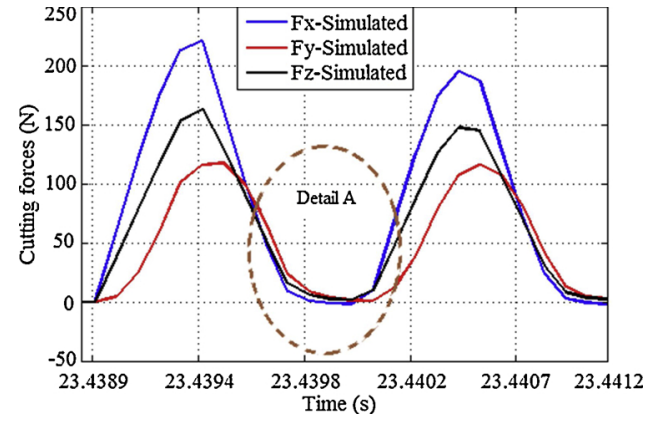

Fig. 17. Simulated cutting forces, $N=23,750.4 \mathrm{rev} / \mathrm{min}, a_{e}=1 \mathrm{~mm}, a_{p}=1 \mathrm{~mm}$, $f_{z}=0.1 \mathrm{~mm} /$ tooth $/ \mathrm{rev}$, the runout measured on tooth (1) is $e=6 \mu \mathrm{m}$ and its eccentricity is $\rho=67^{\circ}$.

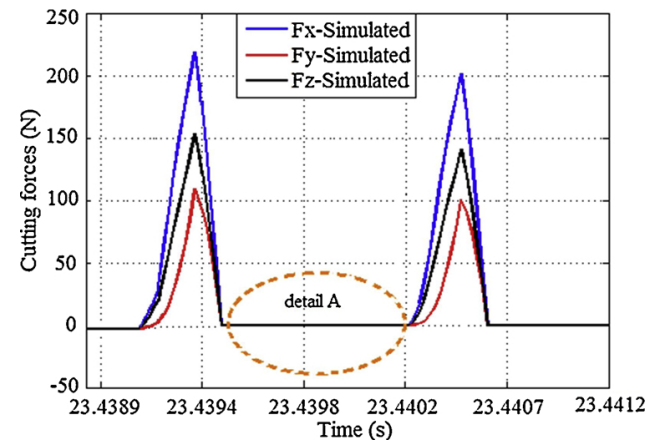

Fig. 18. Simulated cutting forces using conventional method, $N=23,750.4 \mathrm{rev} /$ min, $a_{e}=1 \mathrm{~mm}, a_{p}=1 \mathrm{~mm}, f_{z}=0.1 \mathrm{~mm} /$ tooth $/ \mathrm{rev}$, the runout measured on tooth (1) is $e=6 \mu \mathrm{m}$ and its eccentricity is $\rho=67^{\circ}$.

shown in Fig. 18. The conventional method supposes that the engagement region between the tooth and the workpiece is zero near the tool tip point. This means that the first tooth disengaged from the material and after an uncommitted period, the second tooth engaged on the material which produces a non-engagement zone as shown in detail (A).

The cutting forces simulated by the new method show good correlations with the measured one and validates the new model of the (CWE) region and the instantaneous undeformed chip thickness calculations.

\section{Conclusion}

In this paper, an analytical method based on the true tooth trajectory is proposed to calculate accurately the cutting forces by extracting the exact cutter and workpiece engagement region and the instantaneous undeformed chip thickness.

The proposed model modifies previous idea of geometrical approximation of the tooth trajectory as a circular one, the chip thickness as a product of the feed per tooth $f_{z}$ and the sinus of the rotary angle $\theta$.

A test for $42 \mathrm{CrMo} 4$ steel under different cutting conditions was introduced and used to validate the proposed model. The predicted results give a good approximation for the forces and the main experimental tendencies. The difference noticed between the measured and simulated values is due to elastoplastic components of cutting forces which are not taken into account in the proposed model. This model is useful to simulate the cutting process in order to enhance machining quality. It can easily be extended to the 5 axis ball end milling in further works.

\section{Acknowledgments}

The work is carried out thanks to the support and funding allocated to the Unit of Mechanical and Materials Production Engineering (UGPM2 / UR17ES43) by the Tunisian Ministry of Higher Education and Scientific Research.

\section{References}

[1] Ju G, Qinghua S, Zhanqiang L. Prediction of cutter-workpiece engagement for fiveaxis ball-end milling. Mater Sci Forum 2014:800-801:254-8.

[2] Zhiyang Y. Finding cutter engagement for ball end milling of tessellated free-form surfaces. Long Beach, California USA: ASME I Design Eng Tech Conf; 2005.

[3] Boz Y, Erdim H, Lazoglu I. A comparison of solid model and three-orthogonal dexelfield methods for cutter-workpiece engagement calculations in three- and fiveaxis virtual milling. I J Adv Manuf Technol 2015;81:811-23.

[4] Kiswanto G, Hendriko H, Duc E. An analytical method for obtaining cutter workpiece engagement during a semi-finish in five-axis milling. Comput Des 2014;55:81-93.

[5] Ozturk B, Lazoglu I. Machining of free-form surfaces. Part I: analytical chip load. I J Mach Tools Manuf 2006;46-7:728-35.

[6] Iwabe H, Shimizu K, Sasaki M. Analysis of cutting mechanism by ball end mill using 3D-CAD. JSME I J Series C 2006;49-1:28-34.

[7] Sato Y, Sato R, Shirase K. Influence of motion errors of feed drive systems onto machined surface generated by ball end mill. J Adv Mech Des Syst Manuf $2014 ; 8-4: 1-10$

[8] Nishio K, Sato R, Shirase K. Influence of motion error of feed drive systems on machined surface. J Adv Mech Des Sys Manuf 2012;6-6:781-91.

[9] Erdim H, Lazoglu I, Ozturk B. Feedrate scheduling strategies for free-form surfaces. I J Mach Tools Manuf 2006;46:747-57.

[10] Gong X, Feng HY. Cutter-workpiece engagement determination for general milling using triangle mesh modeling. J of Comp Des and Eng 2016:3:151-60.

[11] Ozturk E, Taner TL, Budak E. Investigation of lead and tilt angle effects in 5-axis ball-end milling processes. I J Mach Tools Manuf 2009;49:1053-62.

[12] Erdim H, Sullivan A. Cutter workpiece engagement calculations for five-axis milling using composite adaptively sampled distance fields. Procedia CIRP 2013;8:438-43.

[13] Sun Y, Ren F, Guo D, Jia Z. Estimation and experimental validation of cutting forces in ball end milling of sculptured surfaces. I J Mach Tools Manuf 2009;49:1238-44.

[14] Boz Y, Erdim H, Lazoglu I. A comparison of solid model and three-orthogonal dexelfield methods for cutter-workpiece engagement calculations in three- and fiveaxis virtual milling. I J Adv Manuf Technol 2015;81:811-23.

[15] Mamedov A, Lazoglu I. Micro ball-end milling of freeform titanium parts. Adv Manuf 2015;3:263-8.

[16] Zeroudi N, Fontaine M, Necib K. Prediction of cutting forces in 3-axes milling of sculptured surfaces directly from CAM tool path. J Intell Manuf 2012;23:1573-87.

[17] Sai L, Bouzid W, Zghal A. Chip thickness analysis for different tool motions for adaptive feed rate. Mater Process Technol 2008;28:213-20.

[18] Yucesan G, Altıntaş Y. Prediction of ball end milling forces. J Eng for Ind 1996;118-1:95-103.

[19] Ko JH, Cho DW. 3D ball-end milling force model using instantaneous cutting force coefficients. J Manuf Sc Eng 2005;127-1:1-12.

[20] Altintas Y, Lee P. Mechanics and dynamics of ball end milling. J Manuf Sc Eng 1998;120-4:684-92.

[21] Sai L, Bouzid W, Dessein W. Cutter workpiece engagement region and surface topography prediction in five-axis ball-end milling. Mach Sci Technol 2017:1532-2483.

[22] Salami R, Sadeghi MH, Motakef B. Feed rate optimization for 3-axis ball-end milling of sculptured surfaces. I J Mach Tools Manuf 2007;47:760-7.

[23] Lee P, Altintas Y. Prediction of ball-end milling forces from orthogonal cutting data. I J Mach Tools Manuf 1996;36:1059-72.

[24] Ozturk B, Lazoglu I. Machining of free-form surfaces. Part I: analytical chip load. I J Mach Tools Manuf 2005;46-7:728-35.

[25] Guzel BU, Lazoglu I. Increasing productivity in sculpture surface machining via offline piecewise variable federate scheduling based on the force system model. I J Mach Tools Manuf 2004;4:21-8.

[26] Liu X-W, Cheng K, Longstaff AP, Widiyarto MH, Ford D. Improved dynamic cutting force model in ball-end milling. Part I: theoretical modelling and experimental calibration. I J Adv Manuf Technol 2005;26:457-65.

[27] Cheng K. Machining dynamics: theory. London: Applications and Practices, Springer; 2008. November.

[28] Baburaj M, Ghosh A, Shunmugam MS. Development and experimental validation of a mechanistic model of cutting forces in micro-ball end milling of full slots. Mach Sci Techol 2018;0:1-24. 